\title{
Uma história da Inquisição em Portugal e no seu império
}

Evergton Sales Souza*

Marcocci, Giuseppe; Paiva, José Pedro. História da Inquisição portuguesa (15361821). Lisboa: A Esfera dos Livros, 2013.

A produção historiográfica sobre a Inquisição portuguesa, em particular aquela relativa a diferentes aspectos da ação inquisitorial, não tem parado de crescer nas últimas três décadas. Contudo, até o presente momento, nenhuma verdadeira tentativa de síntese da história dessa instituição havia sido tentada. Talvez a massa bibliográfica e documental a ser necessariamente manuseada numa tal empresa fosse um dos motivos que concorriam para que especialistas não encarassem esse desafio. Mas, ao mesmo tempo, os estudos publicados nos últimos vinte anos sobre a estrutura e organização da Inquisição portuguesa também proporcionaram um melhor conhecimento de vários aspectos sem os quais seria temerária a realização do ambicioso projeto de escrever uma síntese de sua história. Dois importantes historiadores do mundo português moderno, José Pedro Paiva, professor da Universidade de Coimbra, e Giuseppe Marcocci, professor da Università degli Studi della Tuscia, em Viterbo, encararam o desafio e uniram seus esforços a fim de escrever uma primeira história da
Inquisição portuguesa desde sua fundação, em 1536, ao ocaso, em 1821.

O livro contém dezoito capítulos que estão distribuídos em cinco partes, cada uma delas correspondendo a um período da história da Inquisição portuguesa. Assim, vislumbra-se uma proposta de periodização que principia em 1536, com a fundação definitiva do Tribunal, e vai até 1605 , com a primeira grande crise enfrentada pela Inquisição. Crise que atinge seu clímax com a concessão do perdão geral aos cristãos-novos, dado pelo papa em breve de 23 de agosto de 1604 — o qual só viria a ser publicado em Goa no ano de 1705. A Inquisição sofreu grande derrota nesse episódio, tanto mais que o breve era fruto dos esforços de famílias cristãs-novas que denunciaram em Roma as arbitrariedades cometidas pelo Tribunal português e conseguiram convencer - a custo, inclusive, de promessas de vultosas somas - a coroa espanhola a apoiar suas demandas junto à cúria romana. $\mathrm{O}$ segundo período se estende de 1605 a 1681 e configura-se como época de apogeu do Tribunal que, recuperado da derrota de 1604, intensificaria e ampliaria seu raio de ação na sociedade portuguesa até novamente estalar uma grave crise que culminaria com a sua suspensão pelo papa, em 1674. O restabejunto da Universidade Federal da Bahia. Salvador, BA, Brasil. E-mail: evergton@pq.cnpq.br. 
lecimento do Tribunal, em 1681, é a página final de um período e a abertura de outro que seria marcado pela "busca de um novo caminho", no qual estáo ainda patentes os traços distintivos que denotam o prestígio da instituição na sociedade portuguesa, bem como sua estratégia de se fazer admirar, respeitar e temer pelo teatro do poder e pelo espetáculo do castigo. Entretanto, ao avançar do século XVIII, alguns problemas irão mostrar os limites do novo caminho. A crise aberta pela querela do sigilismo, na década de 1740, deixaria marcas profundas na história das relaçôes entre a Inquisição e o episcopado, solapando uma das bases do seu poder e legitimidade. Esta fase que os autores chamaram de "Inquisição barroca" se estendeu até 1755 , quando após o terremoto e com Sebastiâo José de Carvalho e Melo a ganhar mais e mais poder no seio do governo, inaugura-se uma nova época na qual o arrefecimento à perseguição aos cristãos novos e o declínio do poder e prestígio do Tribunal vão se tornando uma realidade palpável. Do nosso ponto de vista, esta data se configura como a que coloca mais problemas nesse esforço de periodização empreendido por Marcocci e Paiva. Enquanto as outras datas marcam momentos críticos ligados à própria história da instituição, aqui se trata de um evento maior, o terremoto, mas que não tem ligação direta à instituição, a não ser, evidentemente, pelo fato de os Estaus terem vindo abaixo com o terremoto. Poderíamos indagar, por exemplo, por que não fazer terminar a fase barroca em 1750 , ano da morte de d. Nuno da Cunha e fim do longo reinado de d. João V? Mas, deve-se convir que, no presente caso, avançar ou recuar cinco anos é um problema menor frente ao trabalho desenvolvido por esses autores. O certo é que a nova fase será marcada pelo signo de sua dominação pelo Estado. Com efeito, a instituição submeteu-se inteiramente, como nunca antes o fizera, aos objetivos do centro de poder político. Despojada de seus inimigos de sempre, os cristãos-novos, ela definha até sua extinção, em 1821. É verdade que os autores optaram por tratar do fim do Tribunal na quinta e última parte da obra. Fizeram-no, contudo, observando uma lógica particular à exposição do texto, estabelecendo uma ligaçáo coerente entre a extinção da instituição, que àquela altura já não era mais do que um corpo moribundo, e a sua emergência como objeto de memória e história estudado e debatido desde então.

Ao conhecimento da bibliografia atinente ao tema os autores desta obra aliaram o das fontes documentais. Aqui repousa uma de suas características distintivas: trata-se de síntese que náo abre mão da construçáo de um conhecimento histórico largamente fundamentado na documentação disponível. Isto faz com que o livro seja lido com muito proveito tanto pelo público náo especialista quanto por aquele especializado, pois ao tempo em que condensa num único volume um conhecimento esparso em múltiplos livros e artigos, apresenta também novos problemas e novas conclusóes retiradas de um conhecimento imediato das fontes. Daqui também se origina uma compreensão da história da Inquisição que consegue manter um distanciamento benéfico ao exame desse objeto táo complexo e que desperta, por 
vezes, discursos e análises eivados de passionalidades. Marcocci e Paiva levam ao pé da letra o ensinamento de Marc Bloch sobre o ofício do historiador e seu dever de compreensão - e não julgamento - dos fatos estudados. Náo se trata de adotar uma atitude complacente em relação ao significado dessa instituição na história da humanidade, mas de procurar compreendê-la no seu devido contexto. Os autores explicitam isto ao afirmarem que:

a Inquisição é, sem dúvida, um símbolo dos excessos de desumanidade a que se pode chegar em nome da religiáo e do que se considerava a verdade. Ainda assim, representa também uma instituição filha do seu tempo que, para ser seriamente compreendida, precisa de ser estudada no seu contexto e nas suas consequências concretas. (p. 14)

Apresentar a Inquisição como "filha do seu tempo" pode, à primeira vista, parecer uma fórmula fácil, mas sua real profundidade revela-se na medida em que os autores vão desenvolvendo uma das ideias centrais do livro e que se encontra magistralmente exposta no capítulo 6, "O medo de uma sociedade impura”. Evidencia-se que uma lógica de intolerância e ideais de pureza de sangue estavam difusos na sociedade. Esses elementos explicam muito da origem e do desenvolvimento do Tribunal do Santo Ofício em Portugal. Compreende-se, assim, que a instituição não foi imposta, mas desejada por amplos setores da sociedade tomados por uma obsessão antijudaica. Esses mesmos setores, com o passar do tempo, pressionaram a coroa a adotar políticas cada vez mais discriminatórias em relação aos cristãos-novos. Aqui se descortina mais uma linha de força deste livro que ao contar a história da Inquisição não o faz a partir de um olhar circunscrito à instituição, mas procurando observar sua inserção no - e sua interação com o - contexto social, cultural, político e econômico de seu tempo.

Para Paiva e Marcocci a Inquisiçáo foi, sobretudo, um tribunal eclesiástico que tinha seu lugar junto a outras instâncias que formavam o complexo ordenamento jurídico português da época moderna, mas também foi um lugar de poder (p. 15). Ao longo da obra, nota-se como o tribunal português, cuja rápida ascensão se deveu ao apoio da coroa, mas também aos ventos da contrarreforma, adaptou-se aos jogos de poder na busca de construir e manter sua relativa independência vis-à-vis do poder monárquico e, embora subordinada ao papa, procurando não se dobrar inteiramente ao seu poder. Nesse sentido, a dinâmica das relaçóes entre Inquisição, monarquia e Roma apontada na obra pode nos fazer pensar no dilema do clero galicano em sua vontade de autonomia em relaçáo ao rei e ao papa. Contudo, a similitude fica restrita a este campo, pois do ponto de vista eclesiológico a Inquisição portuguesa jamais flertou com as ideias galicanas, demasiado episcopalistas e pouco favoráveis à instituição inquisitorial.

Esta História da Inquisição portuguesa exprime uma constante preocupação em descrever e analisar a ação inquisitorial numa escala geográfica que extrapola os li- 
mites do Portugal continental. Além da necessária atenção dada ao tribunal de Goa, é dispensado especial cuidado ao exame da ação do tribunal em todo o ultramar português, e particularmente no Brasil. $\mathrm{O}$ peso conferido ao império ultramarino ao longo do livro, com quatro capítulos inteiramente consagrados ao seu estudo, revela não só a visão abrangente que os autores têm do objeto estudado, mas também uma escolha que transcende as fronteiras de um campo historiográfico específico, refletindo uma tendência compartilhada por diversos historiadores, entre os quais me incluo. Nesse sentido, a obra é mais uma excelente prova de que o conhecimento histórico sobre o mundo português moderno tem muito a ganhar quando estendemos o campo de visão para além dos limites do Portugal continental ou de uma área específica de seu império.

Escrito em muito bom estilo, o livro deixa-se ler facilmente. Ao longo de suas 607 páginas identificamos poucas gralhas, todas facilmente corrigíveis e que não comprometem a qualidade do texto. A título de exemplo pode-se mencionar o caso do breve Inter luculenta, de 1737, que iliba d. Inácio de Santa Teresa das suspeitas de jansenismo que haviam sido lançadas contra si em Goa, grafado "Inter iuculenta" (p. 300). À página 296, em passagem sobre o cristão-novo Francisco de Sá, há erro no século apontado para o seu anterior encarceramento. Por fim, nota-se um problema no gancho do parágrafo final do capítulo 11 (p. 304) que remete o leitor não para o imediatamente seguinte, mas para o capítulo 13, que discorre sobre a Inquisição nos tempos de Pombal.
Também são bastante raras as imprecisões pontuais que notamos na obra. É o caso da menção feita a Bossuet (p. 235). Ali deveria ser dito que seria, em 1677, "futuro bispo" de Meaux, pois ele já havia sido bispo de Condom, entre 1670 e 1671, antes de renunciar àquela mitra a fim de se tornar preceptor do príncipe herdeiro francês. Menos marginal ao objeto da obra é a inexistência de uma advertência ao leitor quanto à composição étnica da Congregação do Oratório em Goa. Trata-se de um aspecto importante a salientar, ainda mais num passo em que são abordados problemas relativos às tensóes locais e ao prestígio social conferido pela participação em atividades relacionadas com o Santo Ofício ( $p$. 319). Por fim, há uma ou outra ausência a lamentar na bibliografia, como a do excelente Rosa Egipciaca: uma santa africana no Brasil (Rio de Janeiro: Editora Bertrand do Brasil, 1993), de Luiz Mott, e a do recente Domingos Alvares, african healing, and the intellectual history of the Atlantic world (Chapel Hill: The University of Carolina Press, 2011), de James H. Sweet.

Os poucos problemas assinalados aqui terminam por confirmar a solidez da obra em tela, sem nada ofuscar do seu brilho. Talvez a palavra que melhor a defina seja "equilíbrio". Equilíbrio para não ceder ao mero discurso condenatório, nem à complacência em relação à instituição e à sociedade estudada; para dosar cuidadosamente o uso da bibliografia existente e a imprescindível consulta direta às fontes documentais; para construir um texto suficientemente fluido que agrade ao público em geral e rigoroso, 
inovador e instigante o bastante para tornar-se indispensável aos especialistas.

Por suas muitas qualidades, por seu equilíbrio, esta História da Inquisição Portu- guesa, de José Pedro Paiva e Giuseppe Marcocci constitui um marco na historiografia sobre o tema. Uma obra verdadeiramente incontornável. 